\title{
Managing Care during the COVID-19 Pandemic: The Point of View and Fears of Pediatric Cancer Patients' Families
}

\author{
Olga Nigro, ${ }^{1}$ Giovanna Sironi, ${ }^{1}$ Andrea Ferrari, ${ }^{1}$ Gabriele Tinè, ${ }^{2}$ Gabriele Infante, ${ }^{2}$ Francesco Barretta, ${ }^{2}$ Matteo \\ Silva, ${ }^{1}$ Carlo Alfredo Clerici, ${ }^{3,4}$ Stefano Chiaravalli, ${ }^{1}$ Elisabetta Schiavello,${ }^{1}$ Veronica Biassoni, ${ }^{1}$ Marta Podda, ${ }^{1}$ \\ Cristina Meazza, ${ }^{1}$ Filippo Spreafico,${ }^{1}$ Michela Casanova, ${ }^{1}$ Monica Terenziani, ${ }^{1}$ Roberto Luksch, ${ }^{1}$ Maura
}

Massimino $^{1^{*}}$

\author{
${ }_{1}^{1}$ Pediatric Oncology Unit, Fondazione IRCCS Istituto Nazionale dei Tumori, Milan, Italy \\ ${ }^{2}$ Clinical Epidemiology and Trial Organization Unit, Fondazione IRCCS Istituto Nazionale dei Tumori, Milan, \\ Italy \\ ${ }^{3}$ Department of Oncology and Hemato-Oncology, University of Milan, Milan, Italy \\ ${ }^{4}$ SSD Clinical Psychology, Fondazione IRCCS Istituto Nazionale dei Tumori, Milan, Italy \\ * Correspondence: Dr Maura Massimino, maura.massimino@istitutotumori.mi.it, +390223902588
}

\begin{abstract}
Background: When the COVID-19 pandemic arrived, changes had to be made to several management aspects at our Pediatric Oncology Center. We investigated how the families perceived these changes. (2) Methods: Two questionnaires were developed at the Pediatric Oncology Unit of the Istituto Nazionale dei Tumori in Milan, to explore how the pandemic has affected the experience of patients who had been or were being treated at our hospital, and their families. These were administered to three samples of individuals. (3) Results: Between July and October 2020, 120 questionnaires were administered to parents of patients. The impact of school closures and the impossibility of attending sports and social activities outside the hospital were regarded as important. $77.5 \%$ of parents judged the social distancing to have affected their children. Regarding the changes introduced in the management of the ward and outpatient clinic, most parents' opinions were positive. Differences in the opinions expressed by Groups 2 and 3 were statistically significant on the topic of relationships on the ward and staff workload. The aspect most negatively affected by the pandemic was the support that patients' parents were able to give each other. Regardless of whether patients were treated before the pandemic or after the first lockdown, their parents of all indicated a strong degree of satisfaction with the care received, and with the organizational arrangements. (4) Conclusions: The results of our study point us in the right direction to further improve our daily work and better respond to the needs of our patients and their families.
\end{abstract}

Keywords: COVID-19; pediatric oncology

\section{Introduction}

The COVID-19 pandemic has hit hard in all healthcare settings, obliging the healthcare community to try and deal with this unexpected emergency, with profound effects on how patients and their families are managed.

Cancer units all over the world have found themselves striving to minimize the risk of the virus spreading within hospitals, while providing for the best possible management 
of cases testing positive for COVID-19 and continuing to assure patients the oncological care they need[1-5].

When the pandemic arrived, drastic changes had to be made to several management aspects at our Pediatric Oncology Center. Among the various steps taken, access to the ward and outpatient clinic was restricted, even for educators, teachers, and volunteers (partly to comply with central government legislation). Even the physical presence of clinical psychologists on the wards had to be limited in many cases. Only one parent was allowed during a child's hospital stay, and non-urgent visits were handled by telephone.

Patients and their families had to talk to doctors with masks over their faces or via impersonal phone calls, which made communications more challenging, adding to the anguish of coping with cancer and all the "classical" issues that typically accompany a cancer diagnosis. The need for psychological support in such situations has been globally recognized, and most families were often under huge stress, but restrictions imposed to contain the pandemic and enforced social distancing measures left our patients and their families with fewer relational resources. They could no longer rely on the support of grandparents and friends. They had fewer chances to socialize through schooling activities. Psychosocial support group activities were suspended. Only one parent could be involved in hospital stays[3,5].

Given this situation, we wished to better understand how the new care management arrangements were perceived by our healthcare service users. A first survey was conducted among our adolescent patients to assess their perception of the risk posed by the new coronavirus and their level of stress regarding the COVID-19 pandemic[6]. In the present study, we looked at the patients' families, investigating how changes made to the way we work and approach patients and families since the arrival of the pandemic have been perceived.

\section{Materials and Methods}

Two questionnaires were developed by physicians and psychologists at the Pediatric Oncology Unit of the Istituto Nazionale dei Tumori in Milan, to explore how the pandemic, and its direct and indirect consequences have affected the experience of patients who had been or were being treated at our hospital, and their families. A further goal of the study was to ascertain from the questionnaires administered whether any of the recent organizational adjustments had enhanced the parents' experience with a view to adopting or retaining these changes in the future.

The two separate questionnaires were administered to three different samples of individuals.

One questionnaire was used with 40 parents (or caregivers) looking after 40 patients who experienced the organizational changes made to cope with the pandemic, i.e. patients who had begun their cancer treatments before the pandemic and continued to be treated during the outbreak (Group 1). This questionnaire aimed to investigate: concerns about the risk related directly to COVID-19 infection; the impact of social distancing measures on various aspects of the care pathways and family relationships; and the effects of 
management changes on the pediatric oncology ward and at the outpatient clinic compared with their previous hospital experience.

Another questionnaire was administered to 40 parents looking after 40 patients whose treatments stopped before the pandemic broke out (Group 2), and to another 40 parents looking after 40 patients whose treatments began after the arrival of the pandemic (Group 3). This second questionnaire aimed to compare these two groups of parents (of patients treated before versus after the outbreak of the COVID-19 pandemic), investigating their experience of specific issues, such as the care they received, organizational aspects on the ward and at the outpatient clinic, and the social support network.

Parents were invited to complete the questionnaire during clinical visits or hospital stays. A staff member personally gave each parent a printed copy of the questionnaire and informed them about the aims of the study. The questionnaire was administered in an anonymous format and completed by parents in their own time and without any assistance or supervision on the part of staff members, ensuring the confidentiality of all the data collected.

The questionnaire was approved by the Research Ethics Committee at the Fondazione IRCCS Istituto Nazionale dei Tumori, Milan, Italy (code 178/20 of the Italian National Observatory on Clinical Trials). All the parents involved gave their written informed consent to their participation in the study.

The sample size of the study was not based on any specific objectives. The survey was purely descriptive and aimed to explore how the parents of patients in the care of the INT Pediatric Oncology Unit perceived the direct and indirect consequences of the COVID-19 pandemic.

The following demographic variables were collected for both questionnaires: parents' age, gender, educational qualifications, region of origin, and occupation[7], together with the type of disease and age of the respective patients.

The first and second questionnaires consisted of 32 and 18 questions, respectively, with 5 possible answers: "Not at all", "Slightly", "Moderately", "Very much" and "Extremely".

The items in the first survey were grouped into six subscales concerning: "perception and concerns about the risk associated with COVID-19 infection" (q1.01-q1.05); "impact of social distancing and lockdown measures on personal and family life" (q1.06-q1.13); "effects of changes in the management of the pediatric cancer ward and outpatient clinic compared with the situation before the pandemic" (q1.14-q1.18); "hospital experience relating to cancer treatments during the pandemic" (q1.19-q1.26); "perceptions relating to care providers during the pandemic" (q1.27-q1.30); "suggestions for improving the support available" (q1.31-q1.32).

Parents' and patients' characteristics were summarized in terms of frequencies (absolute and relative) for qualitative variables, and as medians, first and third quartiles for continuous variables.

For the first questionnaire, a descriptive analysis was conducted by grouping the items in the above-mentioned six subscales, obtaining a score for each subscale by 
averaging the cumulative scores of the single items in a given subscale. For subscales 1, 2, 3 and 4, the lower the score, the lower the perception of the risk to parents and patients caused by the pandemic and the organizational changes made to cope with it. For subscales 5 and 6 , the lower the score, the more positive the parents' opinion of their experience. The following parameters were calculated for each subscale: mean, standard deviation (SD), median, first and third quartile, and range of variation.

As for the second questionnaire, the answers given were considered as categorical, continuous, and ordinal categorical, and Fisher's exact tests[8] (F), Wilcoxon-MannWhitney tests[9] (WMW), and Proportional Odds Models[10] (POM) were used, respectively, to assess differences between the answers given by Group 2 and Group 3. The models were used to examine the adjusted differences in two steps. First we ran a POM for each item, including the parents' age, gender, educational qualifications, and region of origin, and the patients' age. Then the values predicted with this model were extracted and input as covariates in a new POM to obtain the adjusted comparisons by means of Wald tests on the regression coefficient of the study group covariate. Absolute and relative frequencies were then calculated for each item. The analyses were run using $\mathrm{R}$ (version 4.0.3).

\section{Results}

Between July and October 2020, 120 questionnaires (40 for each study group) were administered to parents of patients at our Pediatric Oncology Unit. Supplementary Table 1 shows the details collected on the parents (age, gender, educational qualifications, region of origin, occupation) and patients (age and type of tumor). The table shows that our questionnaire was answered mainly by patients' mothers, who accounted for $60 \%$ of Group 1, $72.5 \%$ of Group 2, and $82.5 \%$ of Group 3. The mean age of the sample was 47.5 years for Group 1, 50.5 years for Group 2, and 43.5 years for Group 3.

\subsection{First Questionnaire}

Table 1 shows the 32 questions and answers, while Table 2 shows the results grouped into subscales with the respective mean and median values.

We can see from these mean and median values in Table 2 that parents were concerned about COVID-19 infection, the impact of social distancing, and the effects of changes to care management and the hospital experience (subscales 1-4). On the other hand, they did not perceive a lack of healthcare staff, and they approved of the improvements to care provision (subscales 5-6).

Analyzing Table 1 in detail shows, however, that the impact of school closures was regarded as important: $52.5 \%$ of respondents felt that their children were from moderately to extremely affected by being unable to attend school (question 1.09). The impossibility of attending sports and social activities outside the hospital was also regarded as moderately to extremely important by $62.5 \%$ of parents (question 1.11). The impact of social distancing on daily life was attributed mainly to distancing from family members and friends (question 1.13): $77.5 \%$ of parents judged this to have affected their children from moderately to extremely. Less than half of the parents answering the questionnaire 
(42.5\%) reported experiencing economic difficulties or concerns compared with before the pandemic (question 1.07).

Regarding the changes introduced in the management of the ward and outpatient clinic (triage, strict time slots for medical visits, separate routes for patients according to need, "telephone consultations", but also single rooms), most parents' opinions were positive (subscale 3 in Table 2: mean 2.1, median 2.0 [range 1.8-2.4]). There was also general satisfaction with the handling of emergencies and the support given to patients and families, with $85 \%$ of parents giving positive opinions on these matters (question 1.14)

Meanwhile, $60 \%$ of parents found that restricting hospital access to only one of the parents was moderately to extremely difficult to cope with, both for the family as a whole and for the child receiving treatment (questions 1.19 and 1.20). The banning of visitors (family and friends) during hospital stays also had an impact according to 52.5\% of respondents.

Table 1. Questionnaire 1: questions and answers.

\begin{tabular}{|c|c|c|c|c|c|c|}
\hline \multicolumn{2}{|r|}{ Item } & \multirow{2}{*}{$\begin{array}{l}\text { Not at all } \\
\mathbf{n}(\%) \\
2(5.0)\end{array}$} & \multirow{2}{*}{$\begin{array}{c}\text { Slightly } \\
\mathbf{n}(\%) \\
4(10.0)\end{array}$} & \multirow{2}{*}{$\begin{array}{l}\text { Moderately/Fairly } \\
\qquad \mathbf{n}(\%) \\
21(52.5)\end{array}$} & \multirow{2}{*}{$\begin{array}{l}\text { Very much } \\
\text { n(\%) } \\
5(12.5)\end{array}$} & \multirow{2}{*}{$\begin{array}{c}\text { Extremely } \\
\mathbf{n}(\%) \\
8(20.0)\end{array}$} \\
\hline q1.01 & $\begin{array}{l}\text { Are you afraid your child might become infected with } \\
\qquad \text { COVID-19? }\end{array}$ & & & & & \\
\hline q1.02 & $\begin{array}{l}\text { Are you afraid your child might have serious } \\
\text { complications of a COVID-19 infection? }\end{array}$ & $2(5.0)$ & $5(12.5)$ & $23(57.5)$ & $3(7.5)$ & $7(17.5)$ \\
\hline q1.03 & $\begin{array}{l}\text { Are you afraid of becoming infected with COVID-19 } \\
\text { yourself? }\end{array}$ & $3(7.5)$ & $10(25.0)$ & $20(50.0)$ & $2(5.0)$ & $5(12.5)$ \\
\hline q1.04 & Are you afraid of developing serious complications? & $3(7.5)$ & $11(27.5)$ & $14(35.0)$ & $8(20.0)$ & $4(10.0)$ \\
\hline q1.05 & $\begin{array}{l}\text { Have you experienced the threat of COVID-19 with } \\
\text { anguish? }\end{array}$ & $4(10.0)$ & $5(12.5)$ & $16(40.0)$ & $11(27.5)$ & $4(10.0)$ \\
\hline q1.06 & $\begin{array}{l}\text { Do you think that the changes imposed on society (i.e. } \\
\text { closure of shops, gatherings forbidden, stay-home rules } \\
\text { except for demonstrable reasons of necessity) have had a } \\
\text { strong impact on your daily life? }\end{array}$ & $4(10.0)$ & $9(22.5)$ & $16(40.0)$ & $6(15.0)$ & $5(12.5)$ \\
\hline q1.07 & $\begin{array}{l}\text { Compared to the time before the pandemic, did you } \\
\text { experience difficulties or worries about your economic } \\
\text { situation being aggravated by having a sick child? }\end{array}$ & $13(32.5)$ & $10(25.0)$ & $11(27.5)$ & $4(10.0)$ & $2(5.0)$ \\
\hline q1.08 & $\begin{array}{l}\text { Do you think there have been family conflicts and } \\
\text { communication difficulties in connection with the } \\
\text { pandemic? }\end{array}$ & $20(50.0)$ & $13(32.5)$ & $4(10.0)$ & $3(7.5)$ & $0(0)$ \\
\hline q1.09 & $\begin{array}{l}\text { Do you think being unable to physically attend school } \\
\text { (all grades) was a problem for your child? }\end{array}$ & $13(32.5)$ & $6(15.0)$ & $12(30.0)$ & $5(12.5)$ & $4(10.0)$ \\
\hline q1.10 & $\ldots$ and for your family? & $12(30.0)$ & $12(30.0)$ & $9(22.5)$ & $3(7.5)$ & $4(10.0)$ \\
\hline q1.11 & $\begin{array}{l}\text { Do you think the suspension of games, sports and social } \\
\text { activities outside the hospital was a problem for your } \\
\text { child? }\end{array}$ & $7(17.5)$ & $8(20.0)$ & $18(45.0)$ & $5(12.5)$ & $2(5.0)$ \\
\hline
\end{tabular}




\begin{tabular}{|c|c|c|c|c|c|c|}
\hline q1.12 & $\ldots$ and for your family? & $5(12.5)$ & $13(32.5)$ & $14(35.0)$ & $5(12.5)$ & $3(7.5)$ \\
\hline q1.13 & $\begin{array}{l}\text { Do you think the lack of family ties due to the pandemic } \\
\text { (isolation from grandparents, less contact with social } \\
\text { networks) has been a problem for your child and for your } \\
\text { family in general? }\end{array}$ & $2(5.0)$ & $7(17.5)$ & $17(42.5)$ & $5(12.5)$ & $9(22.5)$ \\
\hline q1.14 & $\begin{array}{l}\text { Do you think the way the pediatric outpatient clinic } \\
\text { coped with the emergency (telephone calls to provide } \\
\text { updates on a patient's state of health, reserved entrances, } \\
\text { body temperature screening at entrance, distribution of } \\
\text { hand sanitizer, distribution of face masks) was } \\
\text { inadequate, given the situation? }\end{array}$ & $11(27.5)$ & $23(57.5)$ & $6(15.0)$ & $0(0)$ & $0(0)$ \\
\hline q1.15 & $\begin{array}{l}\text { Do you think the changes made to the procedures for } \\
\text { managing admissions and outpatient visits (telephone } \\
\text { screening, strict time slots, separation of routes for } \\
\text { different patients' needs, "telephone visits") had a } \\
\text { negative effect? }\end{array}$ & $11(27.5)$ & 19 ( 47.5 ) & $9(22.5)$ & $0(0)$ & $1(2.5)$ \\
\hline q1.16 & $\begin{array}{l}\text { Do you think the smaller number of patients in the } \\
\text { outpatient clinic gave doctors less time to devote to your } \\
\text { child? }\end{array}$ & $10(25.0)$ & $10(25.0)$ & $19(47.5)$ & $0(0)$ & $1(2.5)$ \\
\hline q1.17 & $\begin{array}{c}\text { Do you think a hospital stay in a single room is less } \\
\text { preferable for you? }\end{array}$ & $15(37.5)$ & $14(35.0)$ & $8(20.0)$ & $0(0)$ & $3(7.5)$ \\
\hline $\mathrm{q} 1.18$ & ... and for your child? & $16(40.0)$ & $11(27.5)$ & $9(22.5)$ & $2(5.0)$ & $2(5.0)$ \\
\hline q1.19 & $\begin{array}{l}\text { Do you think allowing only one parent to stay in hospital } \\
\text { with a child (without the opportunity for parents to } \\
\text { change places) was a source of difficulty for your family } \\
\text { (i.e. for other children left at home with only one parent)? }\end{array}$ & $9(22.5)$ & $7(17.5)$ & $7(17.5)$ & $6(15.0)$ & $11(27.5)$ \\
\hline q1.20 & $\begin{array}{l}\text {... and for your child (i.e. always staying in hospital with } \\
\text { mum, without being able to see dad, or vice versa)? }\end{array}$ & $8(20.0)$ & $7(17.5)$ & $7(17.5)$ & $10(25.0)$ & $8(20.0)$ \\
\hline $\mathrm{q} 1.21$ & $\begin{array}{l}\text { Do you think banning visits from family and friends } \\
\text { during hospital stays was a problem for your family? }\end{array}$ & $10(25.0)$ & $9(22.5)$ & $9(22.5)$ & $4(10.0)$ & $8(20.0)$ \\
\hline $\mathrm{q} 1.22$ & ... and for your child? & $9(22.5)$ & $9(22.5)$ & $10(25.0)$ & $3(7.5)$ & $9(22.5)$ \\
\hline q1.23 & $\begin{array}{l}\text { Do you think the reduction of games and educational } \\
\text { activities to support community life on the ward was a } \\
\text { problem for your family? }\end{array}$ & $7(17.9)$ & $10(25.6)$ & $10(25.6)$ & $6(15.4)$ & $6(15.4)$ \\
\hline $\mathrm{q} 1.24$ & ... and for your child? & $6(15.0)$ & $12(30.0)$ & $11(27.5)$ & $6(15.0)$ & $5(12.5)$ \\
\hline $\mathrm{q} 1.25$ & $\begin{array}{l}\text { Do you think conducting supportive interviews with } \\
\text { doctors and psychologists while wearing personal } \\
\text { protective equipment (such as masks) and adopting } \\
\text { distancing measures was unsatisfactory? }\end{array}$ & $8(20.0)$ & 19 ( 47.5 ) & $12(30.0)$ & $0(0)$ & $1(2.5)$ \\
\hline $\mathrm{q} 1.26$ & $\begin{array}{l}\text { Do you think conducting supportive interviews with } \\
\text { doctors and psychologists while adopting distancing } \\
\text { measures may have created potential opportunities for }\end{array}$ & $18(45.0)$ & $6(15.0)$ & $7(17.5)$ & $7(17.5)$ & $2(5.0)$ \\
\hline
\end{tabular}




\begin{tabular}{|c|c|c|c|c|c|c|}
\hline & $\begin{array}{l}\text { misunderstandings, undermining the effectiveness of } \\
\text { such interventions? }\end{array}$ & & & & & \\
\hline q1.27 & $\begin{array}{l}\text { During the pandemic did you perceive an increase in the } \\
\text { level of stress among care operators? }\end{array}$ & $12(30.0)$ & $9(22.5)$ & $15(37.5)$ & $3(7.5)$ & $1(2.5)$ \\
\hline q1.28 & $\begin{array}{l}\text { In your experience during the pandemic, do you feel that } \\
\text { you received less attention during your child's cancer } \\
\text { treatment? }\end{array}$ & $34(85.0)$ & $1(2.5)$ & $4(10.0)$ & $1(2.5)$ & $0(0)$ \\
\hline q1.29 & $\begin{array}{l}\text { In your experience during the pandemic, do you feel that } \\
\text { you received less attention regarding the psychosocial } \\
\text { sphere? }\end{array}$ & $30(75.0)$ & $5(12.5)$ & $3(7.5)$ & $1(2.5)$ & $1(2.5)$ \\
\hline $\mathrm{q} 1.30$ & $\begin{array}{l}\text { In your experience during the pandemic, do you feel that } \\
\text { you received less attention in the area of nursing care? }\end{array}$ & $36(90.0)$ & $2(5.0)$ & $2(5.0)$ & $0(0)$ & $0(0)$ \\
\hline q1.31 & $\begin{array}{l}\text { Do you think the COVID-19 pandemic has affected the } \\
\text { quality of care your child received? }\end{array}$ & $33(82.5)$ & $4(10.0)$ & $0(0)$ & $2(5.0)$ & $1(2.5)$ \\
\hline $\mathrm{q} 1.32$ & $\begin{array}{l}\text { Do you feel that concern about the COVID-19 pandemic } \\
\text { has outweighed concern about your child's illness? }\end{array}$ & $30(75.0)$ & $9(22.5)$ & $1(2.5)$ & $0(0)$ & $0(0)$ \\
\hline
\end{tabular}

Table 2. Six subscales of questionnaire 1.

\begin{tabular}{|c|c|c|c|c|}
\hline & Subscales & Mean (SD) & Median (first-third quartile) & Min - Max \\
\hline 1 & Concern about COVID-19 infection & $3.1(0.9)$ & $3.0(2.7-3.4)$ & $1.0-5.0$ \\
\hline 2 & Impact of social distancing & $2.6(0.7)$ & $2.5(2.2-3.0)$ & $1.2-4.9$ \\
\hline 3 & $\begin{array}{l}\text { Effects of changes to care management compared with } \\
\text { organization before the pandemic }\end{array}$ & $2.1(0.5)$ & $2.0(1.8-2.4)$ & $1.0-3.4$ \\
\hline 4 & Hospital experience related to cancer care during the pandemic & $2.7(0.9)$ & $2.6(2.1-3.4)$ & $1.1-4.5$ \\
\hline 5 & $\begin{array}{l}\text { How parents perceived care provided by staff during the } \\
\qquad \text { pandemic }\end{array}$ & $1.6(0.6)$ & $1.5(1.0-1.8)$ & $1.0-3.5$ \\
\hline 6 & Opinions regarding improvements to care provision & $1.3(0.6)$ & $1.0(1.0-1.5)$ & $1.0-3.5$ \\
\hline
\end{tabular}

\subsection{Second Questionnaire}

Table 3 shows the results for each pair of items with the answers given by Groups 2 and 3, and the differences between them. Details of the p-values obtained with Fisher's exact test and the Wilcoxon-Mann-Whitney test are provided in Supplementary Table 2.

Differences in the opinions expressed by Groups 2 and 3 were statistically significant on the topic of relationships on the ward and staff workload. Our findings suggest that the aspect most negatively affected by the pandemic was the support that patients' parents were able to give each other, as seen from parents' answers to question 2.11 (from $70.0 \%$ 
to $37.5 \%$, and from $2.5 \%$ to $37.5 \%$ in "very much/extremely" and "not at all /slightly" responses respectively, $\mathrm{p}<0.001)$.

Staff workload was perceived as moderately to extremely excessive by $95 \%$ of parents in Group 2 and 92.5\% of those in Group 3, with an internal shift from "very much" to "moderately", from $47.5 \%$ to $17.5 \%$, and from $40.0 \%$ to $72.5 \%$, respectively, ( $\mathrm{p}=0.010$ question 2.14).

Regardless of whether patients were treated before the pandemic or after the first lockdown, their parents of all indicated a strong degree of satisfaction with the care received (more than 90\% of moderately/very much/extremely responses to questions 2.01, 2.02, and 2.05), and with the organizational arrangements (90\% of moderately/very much/extremely responses to questions 2.12 and 2.13, and 100\% of moderately/very much/extremely responses to questions 2.03 and 2.04).

The financial impact of the disease and the related treatments was considered less important (75\% or less of "not at all /slightly" responses to q16). Family relations suffered slightly (from $67.5 \%$ to $47.5 \%$ and from $12.5 \%$ to $30.0 \%$ in "very much/extremely" and "not at all /slightly" responses, respectively) from the COVID-19 outbreak, while families' social and emotional support remained an important factor $(80 \%$ of "very much/extremely/moderately" responses in q18).

Table 3. Questionnaire 2: results for each pair of items (groups 2 and 3).

\begin{tabular}{|c|c|c|c|c|c|c|c|c|}
\hline \multicolumn{2}{|r|}{ Item } & & Not at all & Slightly & Moderately/Fairly & Very much & Extremely & p-value \\
\hline \multirow[b]{2}{*}{ q2.01 } & \multirow{2}{*}{$\begin{array}{l}\text { Do you consider the } \\
\text { medical care to have been } \\
\text { clinically satisfactory? }\end{array}$} & 2 & $0(0)$ & $0(0)$ & $0(0)$ & $10(25.0)$ & $30(75.0)$ & \multirow[b]{2}{*}{0.271} \\
\hline & & 3 & $0(0)$ & $0(0)$ & $1(2.5)$ & 15 ( 37.5$)$ & $24(60.0)$ & \\
\hline \multirow[b]{2}{*}{ q2.02 } & \multirow{2}{*}{$\begin{array}{l}\text { Do you think the medical } \\
\text { care was satisfactory in } \\
\text { terms of communication? }\end{array}$} & 2 & $0(0)$ & $1(2.5)$ & $2(5.0)$ & $15(37.5)$ & $22(55.0)$ & \multirow[b]{2}{*}{0.311} \\
\hline & & 3 & $0(0)$ & $0(0)$ & $3(7.5)$ & $21(52.5)$ & $16(40.0)$ & \\
\hline \multirow{2}{*}{ q2.03 } & $\begin{array}{l}\text { Do you think the time } \\
\text { spent by doctors during }\end{array}$ & 2 & $0(0)$ & $0(0)$ & $6(15.0)$ & $13(32.5)$ & $21(52.5)$ & \multirow{2}{*}{0.756} \\
\hline & $\begin{array}{c}\text { outpatient visits was } \\
\text { adequate? }\end{array}$ & 3 & $0(0)$ & $0(0)$ & $4(10.0)$ & $18(45.0)$ & $18(45.0)$ & \\
\hline \multirow{2}{*}{ q2.04 } & $\begin{array}{l}\text { Do you think the time } \\
\text { spent by doctors during }\end{array}$ & 2 & $0(0)$ & $0(0)$ & $6(15.0)$ & $14(35.0)$ & $20(50.0)$ & \multirow{2}{*}{0.936} \\
\hline & $\begin{array}{c}\text { inpatient visits was } \\
\text { adequate? }\end{array}$ & 3 & $0(0)$ & $0(0)$ & $6(15.0)$ & $17(42.5)$ & $17(42.5)$ & \\
\hline \multirow{2}{*}{ q2.05 } & Do you think the nursing & 2 & $0(0)$ & $0(0)$ & $2(5.0)$ & $16(40.0)$ & $22(55.0)$ & \multirow{2}{*}{0.101} \\
\hline & care was satisfactory? & 3 & $0(0)$ & $0(0)$ & $1(2.5)$ & $11(27.5)$ & $28(70.0)$ & \\
\hline \multirow{2}{*}{ q2.06 } & $\begin{array}{l}\text { Do you feel you received } \\
\text { the psychological support }\end{array}$ & 2 & $0(0)$ & $4(10.0)$ & $11(27.5)$ & $13(32.5)$ & $12(30.0)$ & \multirow{2}{*}{0.607} \\
\hline & $\begin{array}{l}\text { you needed during your } \\
\text { child's treatment? }\end{array}$ & 3 & $1(2.5)$ & $4(10.0)$ & $13(32.5)$ & $13(32.5)$ & $9(22.5)$ & \\
\hline
\end{tabular}




\begin{tabular}{|c|c|c|c|c|c|c|c|c|}
\hline q2.07 & $\begin{array}{l}\text { Do you think the way the } \\
\text { psychologists on the ward } \\
\text { interact is adequate? }\end{array}$ & 2 & $\begin{array}{c}0(0) \\
2(5.0)\end{array}$ & $\begin{array}{l}8(20.0) \\
4(10.0)\end{array}$ & $\begin{array}{l}9(22.5) \\
8(20.0)\end{array}$ & $\begin{array}{l}10(25.0) \\
18(45.0)\end{array}$ & $\begin{array}{l}13(32.5) \\
8(20.0)\end{array}$ & 0.840 \\
\hline q2.08 & $\begin{array}{l}\text { Do you think the social } \\
\text { support offered on the } \\
\text { ward is helpful? }\end{array}$ & 2 & $\begin{array}{l}0(0) \\
0(0)\end{array}$ & $\begin{array}{l}1(2.5) \\
3(7.5)\end{array}$ & $\begin{array}{l}14(35.0) \\
10(25.0)\end{array}$ & $\begin{array}{l}15(37.5) \\
14(35.0)\end{array}$ & $\begin{array}{l}10(25.0) \\
13(32.5)\end{array}$ & 0.542 \\
\hline q2.09 & $\begin{array}{c}\text { Do you think the } \\
\text { educational support } \\
\text { (school in hospital) is } \\
\text { satisfactory? * }\end{array}$ & 2 & $\begin{array}{l}0(0) \\
0(0)\end{array}$ & $\begin{array}{l}0(0) \\
1(8.3)\end{array}$ & $\begin{array}{l}7(25.0) \\
5(41.7)\end{array}$ & $\begin{array}{l}14(50.0) \\
5(41.7)\end{array}$ & $\begin{array}{l}7(25.0) \\
1(8.3)\end{array}$ & 0.084 \\
\hline q2.10 & $\begin{array}{l}\text { Do you think the games / } \\
\text { educational activities are } \\
\text { useful? }\end{array}$ & 2 & $\begin{array}{l}0(0) \\
0(0)\end{array}$ & $\begin{array}{l}1(2.5) \\
0(0)\end{array}$ & $\begin{array}{l}4(10.0) \\
6(15.0)\end{array}$ & $\begin{array}{l}13(32.5) \\
18(45.0)\end{array}$ & $\begin{array}{l}22(55.0) \\
16(40.0)\end{array}$ & 0.537 \\
\hline q2.11 & $\begin{array}{l}\text { Do you think the } \\
\text { relationships on the ward } \\
\text { (between parents) have } \\
\text { been helpful? }\end{array}$ & 2 & $0(0)$ & $1(2.5)$ & $\begin{array}{l}11(27.5) \\
10(25.0)\end{array}$ & $\begin{array}{l}15(37.5) \\
10(25.0)\end{array}$ & 13 ( 32.5 ) & $<0.001^{* * *}$ \\
\hline $\mathrm{q} 2.12$ & $\begin{array}{l}\text { Do you consider the } \\
\text { organization and rules of } \\
\text { the department to be } \\
\text { adequate? }\end{array}$ & 2 & $0(0)$ & $\begin{array}{l}1(2.5) \\
1(2.5)\end{array}$ & $\begin{array}{l}6(15.0) \\
9(22.5)\end{array}$ & $\begin{array}{l}22(55.0) \\
22(55.0)\end{array}$ & $\begin{array}{l}11(27.5) \\
8(20.0)\end{array}$ & 0.344 \\
\hline q2.13 & $\begin{array}{l}\text { Do you think the } \\
\text { organization of the } \\
\text { outpatient clinic (time } \\
\text { slots, waiting room, time } \\
\text { available for visits) is } \\
\text { adequate? }\end{array}$ & 3 & $1(2.5)$ & $4(10.0)$ & 14 ( 35.0 ) & 14 ( 35.0$)$ & $8(20.0)$ & 0.458 \\
\hline q2.14 & $\begin{array}{c}\text { Do you think the staff } \\
\text { have too high a workload? }\end{array}$ & 3 & $\begin{array}{l}0(0) \\
0(0)\end{array}$ & $\begin{array}{l}2(5.0) \\
3(7.5)\end{array}$ & $\begin{array}{l}16(40.0) \\
29(72.5)\end{array}$ & $\begin{array}{l}19(47.5) \\
7(17.5)\end{array}$ & $\begin{array}{l}3(7.5) \\
1(2.5)\end{array}$ & $0.010^{*}$ \\
\hline q2.15 & $\begin{array}{l}\text { Do you think the staff } \\
\text { have too high an } \\
\text { emotional load? }\end{array}$ & 2 & $\begin{array}{l}1(2.5) \\
4(10.0)\end{array}$ & $\begin{array}{l}2(5.0) \\
2(5.0)\end{array}$ & $\begin{array}{l}16(40.0) \\
17(42.5)\end{array}$ & $\begin{array}{l}15(37.5) \\
12(30.0)\end{array}$ & $\begin{array}{l}6(15.0) \\
5(12.5)\end{array}$ & 0.523 \\
\hline q2.16 & $\begin{array}{l}\text { Do you think your child's } \\
\text { illness and treatment have } \\
\text { had a significant impact } \\
\text { on your family's economic } \\
\text { conditions? }\end{array}$ & 2 & $6(15.0)$ & $14(35.0)$ & 11 ( 27.5 ) & $7(17.5)$ & $2(5.0)$ & 0.957 \\
\hline q2.17 & $\begin{array}{l}\text { Do you feel your child's } \\
\text { illness and treatment have } \\
\text { had a significant impact } \\
\text { on your family } \\
\text { relationships? }\end{array}$ & 2 & $1(2.5)$ & $8(20.0)$ & $9(22.5)$ & $9(22.5)$ & $12(30.0)$ & 0.253 \\
\hline
\end{tabular}




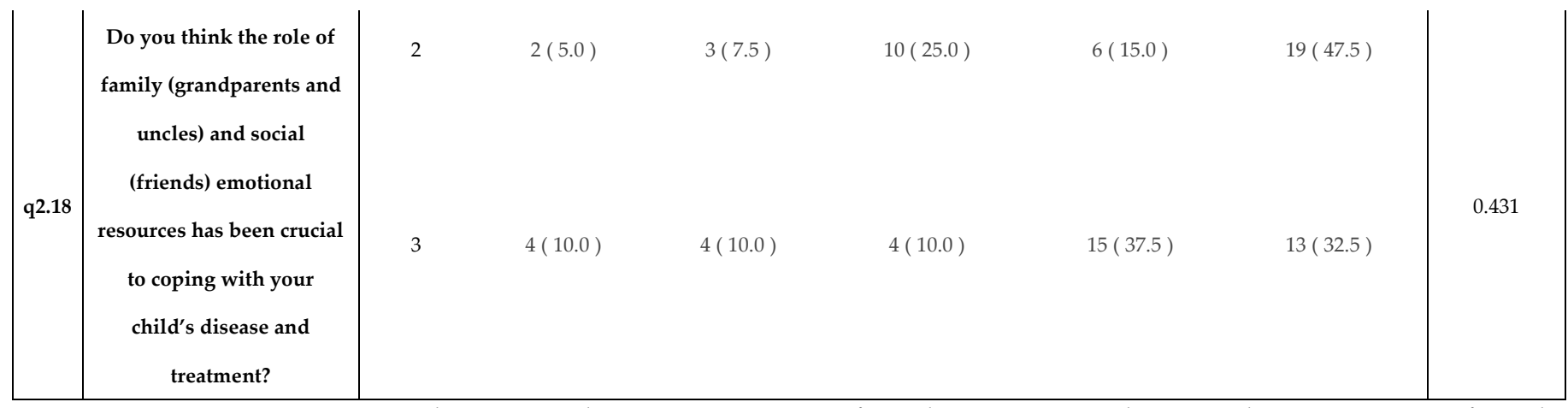

* This question has 12 items missing from the 2-COVID-19 dataset and 28 items missing from the 3-COVID-19 dataset.

POM: Proportional Odds Model, Wald p-value test.

\section{Discussion}

Our study aimed to investigate how the COVID-19 pandemic and consequent organizational adjustments at our hospital affected the experience of families already having to cope with their child's cancer.

The questionnaires revealed families' fears concerning COVID-19, relating to the risk of contagion as well as the psychological repercussions of social distancing. While parents' answers indicated a moderate fear of the infection, they seemed more concerned about the impact of the pandemic on family relations and the habits of daily life.

All the collateral effects of the pandemic, and the changes to social habits imposed by the lockdown to contain it had a relevant impact on the lives of patients and their families (in the economic sphere too). A crucial point underscored by our results concerns how social distancing translated into a limitation on family ties, isolating grandparents and thereby reducing families' social and support networks.

Generally speaking, parents were very satisfied with the new steps taken to manage the ward and outpatient clinic (triage, strict time slots, separate routes for different patients' needs, single rooms). This would go to show that the healthcare operators managed to provide the necessary support for patients and families even in such extremely complex times as in the ongoing pandemic. None of our study groups suggested changes to how their children's care was being managed. They were more critical of the restrictions imposed on access to the ward, with more than $60 \%$ of parents emphasizing the strong impact of the ban on the other parent or other family members or friends visiting their child in hospital.

Our survey also highlighted the importance of relations between members of the a patient's family. The pandemic and related social distancing measures strongly reduced the support among the involved families. Parents also lacked the help of people who were living the same experience and had to learn to spend more time in their ward rooms, in forced isolation. Adolescent patients likewise missed the support that other patients on the ward could normally offer. As we have already reported in other papers, programs dedicated to teenagers (i.e. the Youth Project) had also had to be converted into weekly videoconferences to comply with social distancing requirements[11,12]. 
Another area badly affected by the pandemic concerns patients' education. It is hard to strike the right balance between schools struggling to establish a set of rules to ensure the safety of teachers and other staff, comply with clinical precautions, and somehow resume activities that are fundamentally important to our patients, and to children and young people in general. Uncertainty about their prognosis and the need to concentrate on the treatment of their disease can lead to any plans for the future of a child diagnosed with cancer being put on hold. Continuing their education, in the classroom or in hospital, can help to combat this harmful tendency[13]. Parents reported being from moderately to extremely concerned about their children's schooling in $52.5 \%$ of cases. Due to the restrictions imposed nationwide by law during the first lockdown, our teachers had to continue the in-hospital school program via remote classrooms. The experience suggested that distance learning cannot meet the needs of such particular students as children and adolescents with cancer, however. Attending school in person plays a crucial part in motivating these patients to invest in their studies and their future[13,14].

A further crucial aspect has to do with providing families with adequate psychological support. During the first lockdown in the spring of 2020, legal restrictions obliged us to use modern telecommunications to try and provide this support. We were well aware that, at best, this could only be "better than nothing", but it was far from ideal, so we did our best to restore more adequate in-person psychological support for patients and their families as soon as possible[5].

Our study has various limitations, lying particularly in that it is purely descriptive, and the sample

was limited in size and consisted largely of mothers. Our questionnaires have not been validated and our results only describe the situation at our own institution, the habits and care methods adopted at our unit, and the changes we made to cope with the pandemic.

Despite these limitations, our study could promote discussion and raise awareness regarding a relevant aspect of young patients' care. We believe that listening to parents is crucial to understanding how they have coped with these challenging times, and how changes to how their children's care is managed have affected the experience of the disease pathway. Parents' responses are fundamental now that our approach has transitioned from an "emergency management for a few weeks" to a "risk management for an unspecified period of time". Though we cannot generalize from our results, our patients' and their parents' opinions should be taken into consideration and help us to orient our approach to care.

The results of our study point us in the right direction in order to further improve our daily work and better respond to the needs of our patients and their families.

Author Contributions: Conceptualization, Andrea Ferrari and Maura Massimino; Data curation, Gabriele Infante and Francesco Barretta; Formal analysis, Gabriele Tinè; Investigation, Elisabetta Schiavello; Supervision, Matteo Silva, Carlo Alfredo Clerici, Stefano Chiaravalli, Veronica Biassoni, Marta Podda, Cristina Meazza, Filippo Spreafico, Michela Casanova, Monica Terenziani and Roberto Luksch; Writing - original draft, Olga Nigro and Giovanna Sironi; Writing - review \& editing, Andrea Ferrari and Maura Massimino. 
Supplementary Materials: The following supporting information can be downloaded at: www.mdpi.com/xxx/s1, Table S1: Parents' and patients' characteristics; Table S2: Details of the pvalues obtained with Fisher's exact test (F) and the Wilcoxon-Mann-Whitney test.(WMW).

Funding: Please add: "This research received no external funding"

Institutional Review Board Statement: The study was conducted in accordance with the Declaration of Helsinki, and approved by the Research Ethics Committee at the Fondazione IRCCS Istituto Nazionale dei Tumori, Milan, Italy (code 178/20 of the Italian National Observatory on Clinical Trials).

Informed Consent Statement: Informed consent was obtained from all subjects involved in the study.

Data Availability Statement: Not applicable

Conflicts of Interest: The authors declare no conflict of interest

\section{References}

1. Ferrari A, Zecca M, Rizzari C, et al. Children with cancer in the time of COVID-19: an eight-week report from the six pediatric onco-hematology centers in Lombardia, Italy. Pediatr Blood Cancer. 2020;67(8):e28410.

2. Chiaravalli S, Ferrari A, Sironi G, et al. A collateral effect of the COVID-19 pandemic: Delayed diagnosis in pediatric solid tumors. Pediatr Blood Cancer. 2020 Oct;67(10):e28640.

3. Terenziani M, Massimino M, Biassoni V, et al. SARS-CoV-2 disease and children under treatment for cancer. Pediatr Blood Cancer. 2020 Sep;67(9):e28346.

4. Casanova M, Pagani Bagliacca E, Silva M, et al. How young patients with cancer perceive the Covid-19 (coronavirus) epidemic in Milan, Italy: is there room for other fears? Pediatr Blood Cancer. 2020;67(7):e28318.

5. Clerici CA, Massimino M, Ferrari A. On the clinical psychologist's role in the time of COVID-19, with particular reference to experience gained in pediatric oncology. Psychooncology. 2020 Sep;29(9):1374-1376.

6. Silva M, Barretta F, Luksch R, et al. Adolescents with cancer on privacy: Fact-finding survey on the need for confidentiality and space. Tumori 2021 Jan 28;300891620988357.

7. Bohr, J. (2018). EU-AES Tools: Implementation of the European Socioeconomic Groups Classification (ESeG) using Adult Education Survey Microdata.

8. Hájek J, Šidák Z, Sen PK. Theory of rank tests. 2nd ed. San Diego: Academic Press; 1999.

9. $\quad$ Fisher RA. Statistical methods for research workers. 5th ed. Edinburgh: Oliver \& Boyd; 1934.

10. Agresti, A. Categorical data analysis (Vol. 482). John Wiley \& Sons (2003); (pp. 36-60, 293-314).

11. Ferrari A, Patriccioli A, Silva M, et al. Looking out to see within: A photography project developed by adolescents with cancer during the COVID pandemic. Pediatric Blood and Cancer 2021 May;68(5):e28948.

12. Ferrari A, Pagani Bagliacca E, Veneroni L, et al. Experiencing social isolation (even in the era of COVID-19 pandemic lockdown): teachings through arts from adolescents with cancer. J Adolesc Young Adult Oncol Actions. 2020 Aug 7

13. Adduci A, Ferrari A, Grampa P, et al. How the COVID-19 pandemic has prevented children with cancer from pursuing their schooling in hospital or at home. Childs Nervous System 2021 Mar;37(3):727-728.

14. Darlington AE, Morgan JE, Wagland R et al (2020) COVID-19 and children with cancer: parents' experiences, anxieties and support needs. Pediatr Blood Cancer 21:e28790. 